\title{
Studies of epidermal growth factor receptor inhibition in breast cancer
}

\author{
N J Bundred, K Chan and N G Anderson \\ Academic Department of Surgery, University Hospital of South Manchester, Nell Lane, Manchester M20 8LR, UK \\ (Requests for offprints should be addressed to N J Bundred; Email: bundredn@fs1.with.man.ac.uk)
}

\begin{abstract}
Until recently, there has been little knowledge on the growth control of oestrogen receptor (ER)-negative ductal carcinoma in situ (DCIS) and invasive breast cancer. The recent development of DCIS models, such as transgenic mice, cell-line xenograft models and, importantly, in vivo human DCIS xenograft models has facilitated the investigation and understanding of the control of growth of early pre-invasive breast lesions.

Recent studies have shown that ER-negative DCIS, unlike ER-positive DCIS, is hormone independent and does not respond to anti-oestrogen treatment. Moreover, DCIS of the comedo type utilises type I tyrosine kinase growth factors, such as epidermal growth factor receptor (EGFR) and c-erbB-2, in receptor signalling for growth. New data underscore the importance of EGFR as the major modulating growth factor receptor in the control of proliferation in the breast.

Pre-clinical studies performed on human DCIS xenografts in nude mice suggest a potential role for EGFR tyrosine kinase inhibitors (EGFR-TKIs). More specifically, ZD1839, a novel orally active and selective EGFR-TKI, has been shown to produce a response in DCIS through a decrease in epithelial proliferation. These findings have enhanced our knowledge of signal transduction pathways in cancer and indicate that tyrosine kinase blockade of EGFR has potential for the treatment and chemoprevention of DCIS.

It is hoped that further advances in this area and evaluation of EGFR-TKIs in Phase II/III clinical trials will allow their therapeutic potential as anticancer agents to be appreciated.
\end{abstract}

Endocrine-Related Cancer (2001) 8 183-189

\section{Introduction}

Earlier diagnosis by mammographic screening has resulted in an increase in the incidence of breast cancer. Ductal carcinoma in situ (DCIS) is a pre-invasive breast lesion that accounts for $30 \%$ of cases of screen-detected breast cancer (Ernster et al. 1996). Untreated DCIS progresses to invasive breast cancer in $25-30 \%$ of patients. Greater use of breast conserving surgery and concern in preventing the development of breast cancer with adjuvant anti-oestrogens or other drugs has led to an increasing interest in the mechanism underlying the development of DCIS (Fisher et al. 1998, Ettinger et al. 1999).

The majority $(70 \%)$ of DCIS specimens identified by mammographic microcalcification are of the high-grade comedo type, associated with high proliferative rate, negative oestrogen receptor (ER) status, expression of epidermal growth factor receptor (EGFR), and Neu/c-erbB-2 oncoprotein over-expression (Bobrow \& Millis 1995). ER-negative DCIS, unlike ER-positive DCIS, is expected to be hormone independent and, therefore, unlikely to respond to treatment with anti-oestrogens.

\section{Human ductal carcinoma in situ xenograft model}

The absence of suitable cell lines for DCIS has led to the development of in vivo human DCIS xenograft models in which to study the growth of early proliferative breast lesions. The use of normal human breast tissue xenografts implanted into athymic nude mice demonstrated that more than $95 \%$ of xenografts could be retrieved (Laidlaw et al. 1995). In the same study, oestrogen was shown to increase epithelial proliferation and to induce the expression of progesterone receptor (PR), unlike progesterone, which exhibited no effects.

To determine the effects of oestrogen supplementation on cell proliferation in transplanted DCIS, a novel in vivo animal model was developed, in which human breast DCIS xenografts could be subjected to hormonal manipulation. In 


\section{Bundred et al.: EGFR inhibition in ductal carcinoma in situ}

this model, xenografts of breast tissue (approximately $2 \times$ $2 \times 1 \mathrm{~mm}$ in size) taken from areas of mammographic microcalcification containing histologically verified DCIS in women undergoing mastectomy were implanted into athymic mice (Holland et al. 1997). More than half (58\%) of the xenografts processed for implantation, and subsequently $22.3 \%$ of all xenografts retrieved from the animals, contained foci of DCIS. The median retrieval of DCIS xenografts at the end of each experiment was $94.5 \%$ (range 48-100\%). Xenografts from the majority of specimens $(83 \%)$ survived for up to 56 days in the mice and maintained good architectural and cellular preservation.

In the same study, in order to determine the degree of oestrogen dependence for DCIS growth in relation to steroid receptor status, $50 \%$ of the mice received implants containing oestrogen, giving a concentration of oestradiol of approximately $1400 \mathrm{pmol} / \mathrm{l}$, compared with concentrations of $125 \mathrm{pmol} / \mathrm{l}$ in unsupplemented mice. Levels of cell proliferation in the xenografts recovered after 14, 28, 42 or 56 days in the mice were measured. A significant increase in epithelial proliferation and apoptosis was observed in ER-positive DCIS stimulated by oestrogen $(P<0.001)$, unlike ER-negative DCIS, which showed no change in proliferation or apoptosis in response to oestrogen treatment $(P=0.89)$. The investigators concluded that ER-negative, comedo DCIS lesions appear to be largely oestrogen independent, and that the drive for cell proliferation must be provided by growth factors other than oestrogen. Therefore, anti-oestrogen therapy is not expected to benefit patients with comedo DCIS, whereas ER-positive DCIS responds by a decrease in proliferation or an increase in cell death, or both.

\section{Anti-oestrogen therapy}

To aid further investigation into the effects of anti-oestrogen treatment on DCIS, the same model was used to expose human DCIS xenografts to pure anti-oestrogen therapy and to examine its effects on rates of cell proliferation and apoptotic cell death (Gandhi et al. 2000). The apoptotic index was found to be higher in the day 0 specimens (i.e. tissue representative of that excised from patients at the time of surgery) of ER-negative DCIS lesions than in ER-positive DCIS lesions (1.47\% (range 1.21-1.77\%) compared with $0.32 \%$ (range $0.22-0.45 \%$ ); $P<0.001$ ) (Fig. 1). Similarly, cell proliferation, as measured by the labelling index of the Ki67 nuclear antigen in immunohistochemical staining, was greater in ER-negative DCIS than in ER-positive DCIS lesions (20.6\% (range 18.5-22.9\%) compared with $3.1 \%$ (range $2.2-4.2 \%$ ); $P<0.001$ ). Apoptotic index and labelling index values within ER-negative DCIS did not differ between xenografts exposed to oestrogen or anti-oestrogen treatment compared with controls. In contrast, ER-positive DCIS showed an increase in apoptotic index and labelling index, as expected after 14 days of oestrogen therapy. Anti-oestrogen therapy with ICI 182,780 (Faslodex; AstraZeneca, Alderley Edge, Cheshire, UK) of ER-positive DCIS did not affect the labelling index, but resulted in a greater apoptotic index than was observed in controls. ICI 182,780 also significantly inhibited the expression of PR, an oestrogen-regulated protein, in ER-positive DCIS, as confirmed by immunohistochemical assessment. PR protein expression in day 0 ER-positive xenografts was $39.25 \%$ (range 32.14$47.94 \%$ ), compared with $46.53 \%$ (range $41.68-51.94 \%$ ) after 28 days of oestrogen treatment and $18.17 \%$ (range 17.99 $18.24 \%)$ after 28 days of ICI 182,780 treatment $(P<0.001)$. Therefore, ER-positive DCIS proliferates under hormonal influences and responds to anti-oestrogen therapy, unlike ER-negative DCIS, which is oestrogen independent.

\section{Relevance of anti-oestrogen therapy findings to the clinical situation}

In two studies (Fisher et al. 1999, George et al. 2000), patients were allocated randomly to groups to receive adjuvant tamoxifen or placebo after surgical therapy. The National Surgical Adjuvant Breast and Bowel Project B-24 study (Fisher et al. 1999), in which women were allocated randomly to groups after breast-conserving surgery and localised radiotherapy, demonstrated that women receiving tamoxifen had fewer breast cancer events at 5 years than women receiving placebo (8.2\% compared with $13.4 \% ; P=$ 0.0009). Although a reduced incidence of ipsilateral invasive breast cancer was observed, no reduction in ipsilateral DCIS was detected. In addition, one in three women were reported to be unable to complete the course of tamoxifen treatment because of drug-related side effects or 'personal reasons'. There was also an excess of endometrial cancer and thromboembolic events in the tamoxifen group compared with controls. These adverse events in women with unresponsive DCIS (such as ER-negative DCIS) assume greater clinical concern. It is worth noting that around one-third of the women in this trial were younger than 50 years and the majority of the benefits of tamoxifen were found in this age group.

In the UK DCIS trial (George et al. 2000), which predominantly (93\%) consisted of women aged 50 years or more, patients were allocated randomly to groups to receive radiotherapy and tamoxifen, or either intervention alone. Tamoxifen had no effect in the presence of radiotherapy, although a small but non-significant benefit was detected with tamoxifen therapy in the absence of radiotherapy.

Therefore, although tamoxifen appears to be beneficial in younger women, its value in older women (over 50 years of age) treated for DCIS remains unclear. The mechanism by which tamoxifen reduces recurrent ipsilateral invasive cancer in younger women may relate to the potential of this drug to inhibit the effects of endogenous oestrogen in the breast, rather than to exert direct effects on DCIS. 
Endocrine-Related Cancer (2001) 8 183-189

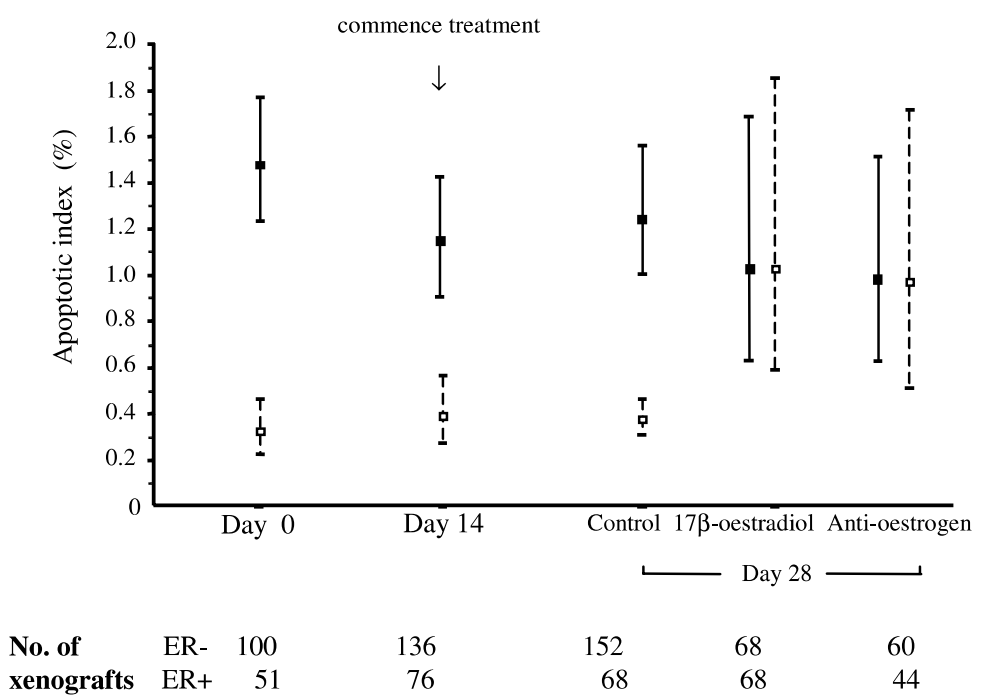

Figure 1 Apoptotic cell death in ER-negative (ER-; solid symbols, solid line) and ER-positive (ER + ; open symbols, dotted line) DCIS. Apoptosis was assessed by morphological assessment of haematoxylin and eosin sections of xenografts retrieved from mice exposed to $17 \beta$-oestradiol, anti-oestrogen, or a control vehicle oil. An apoptotic index was calculated by noting the number of cells showing morphological evidence of apoptotic cell death as a percentage of total number of cells counted in each retrieved xenograft containing DCIS. Results are presented as geometric mean values with their $95 \%$ confidence intervals. The number of xenografts used for each time point is presented beneath the chart for ER-negative and ER-positive DCIS. At day 0 ER-negative DCIS displayed a much greater apoptotic index than ER-positive DCIS. In both subtypes the apoptotic index did not change significantly in the 14-day pre-treatment period; treatment was commenced on day 14. Hormonal manipulation of ER-negative DCIS had no effect on apoptotic cell death compared with control or pre-treatment xenografts. ER-positive DCIS displayed a significant increase in cell death when exposed to 17ß-oestradiol or anti-oestrogen therapy. (Reproduced with permission from Gandhi et al. 2000.)

\section{Role of growth factor receptors in ER-negative ductal carcinoma in situ}

ER-negative DCIS has been shown to express type 1 tyrosine kinase growth factor receptors, such as EGFR and c-erbB-2 (Hanna et al. 1990, Pavelic et al. 1992, Bobrow \& Millis 1995, Gompel et al. 1996, Robertson et al. 1996). Both EGFR and c-erbB-2 have an extracellular receptor binding domain and a cytoplasmic tyrosine kinase domain. On attachment of a ligand, the receptors dimerise, resulting in homodimerisation or heterodimerisation (Wells 1999). Dimerisation results in tyrosine kinase autophosphorylation, which in turn activates a number of intracellular signalling pathways, including the mitogen-activated protein (MAP) kinase signalling pathway (Fig. 2), leading to cell proliferation and prevention of apoptosis (Ullrich \& Schlessinger 1990, Dougall et al. 1993, Muthuswamy et al. 1994, Baselga \& Mendelsohn 1997).

EGFR is a $170 \mathrm{kDa}$ transmembrane glycoprotein expressed on many epithelial cells (Gompel et al. 1996). It is activated by at least six ligands, including epidermal growth factor (EGF), transforming growth factor (TGF)- $\alpha$ and heparin-binding EGF. In a variety of tumours, up-regulated EGFR signalling has been correlated with progression to invasion and metastasis (Wells 1999).
It has been shown that $10-15 \%$ of luminal epithelial cells within the normal breast express steroid hormone receptors; however, dividing cells are steroid hormone receptornegative (Clarke et al. 1997). As human mammary epithelial cells, which are steroid hormone receptor-negative, respond to EGF and insulin-like growth factor (IGF-I), it is likely that growth in the breast is largely controlled by stimulation of these two growth factor receptors (Price et al. 1990, Silverstein 1998).

Stimulation of the IGF-I receptor leads to release of TGF- $\alpha$ from the cell, which transactivates the EGFR in the same cell in an autocrine manner (Roudabush et al. 2000). Therefore, evidence is accumulating that the EGFR is the main receptor pathway associated with epithelial proliferation in the human breast (Gompel et al. 1996).

c-erbB-2 is a $185 \mathrm{kDa}$ transmembrane tyrosine kinase with considerable homology to EGFR, and for which a ligand has not yet been identified. The presence of c-erbB-2 may allow more frequent formation of c-erbB-2 heterodimers and, therefore, augmentation of EGFR cell-surface signalling in the MAP kinase pathway, leading to increased proliferation (Ullrich \& Schlessinger 1990, Dougall et al. 1993, Muthuswamy et al. 1994, Wells 1999).

Heterodimerisation of c-erbB-2 with c-erbB-3 is also a possible explanation for tumour development. Tumour 


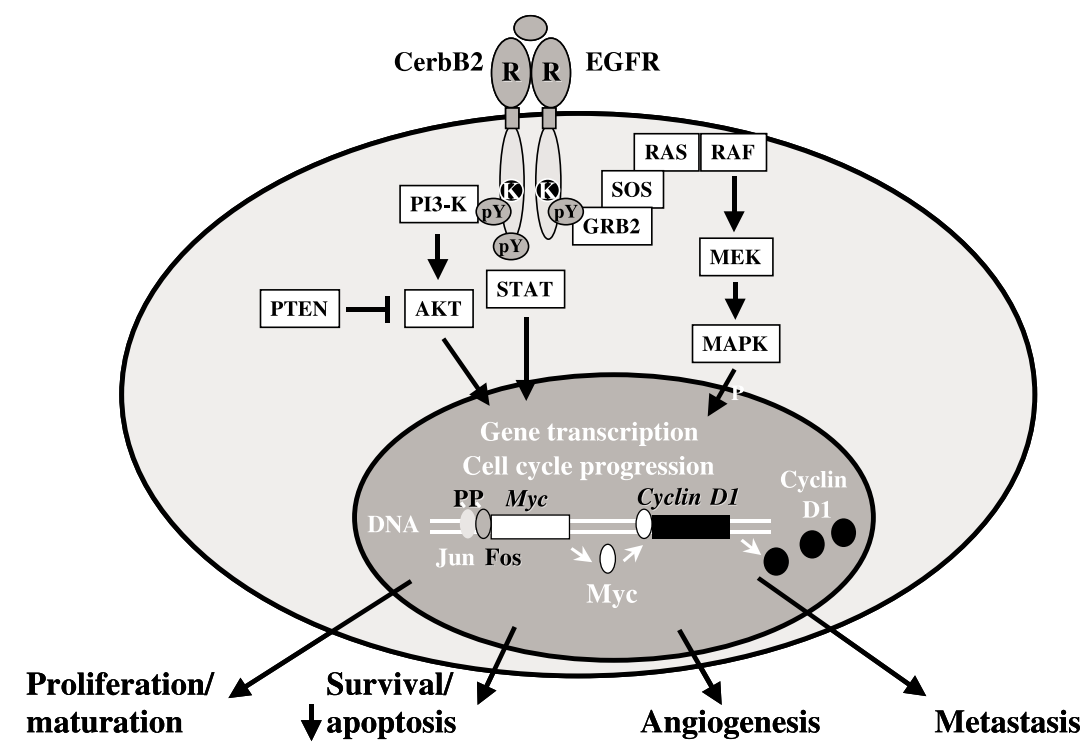

Figure 2 Schematic representation of EGFR signal transduction and its downstream effects. $\mathrm{K}=$ kinase; $\mathrm{pY}=$ phosphotyrosine; R = receptor; PI3-K, phosphatidyl inositol 3-kinase; SOS, Son of Sevenless; GRB2, growth factor receptor-boound 2; MEK, MAP extracellular signal-regulated kinase; MAPK, MAP kinase; PTEN, phosphatase and tensin homologue deleted from chromosome 10; AKT, AKR mouse transforming; STAT, signal transducer and activator of transcription. (Adapted with permission from Baselega et al. 2000.)

progression in mice containing activated c-erbB-2 oncogenes is associated with increased concentrations of phosphorylated c-erbB-2 and c-erbB-3 (Siegel et al. 1999, Dankort \& Muller 2000). Moreover, frequent co-expression of transcripts for both c-erbB-2 and c-erbB-3 has recently been found in a series of primary breast tumours (Siegel et al. 1999). Therefore, metastasis may result from c-erbB-2/c-erbB-3 heterodimers, although the low expression of c-erbB-2 in normal breast suggests that DCIS development involves EGFR rather than c-erbB-2 (Gompel et al. 1996).

In MCF-7 cells transfected with c-erb-B-2 and injected into nude mice to form tumours, resistance to tamoxifen therapy was seen, but the tumours maintained a growth-inhibitory response to oestrogen withdrawal (Benz et al. 1992). Interestingly, c-erbB-2 monoclonal antibody therapy has been shown to produce tumour responses in women with metastatic breast cancer (Cobleigh et al. 1999). Moreover, tyrosine kinase blockade of the EGFR inhibits proliferation or induces apoptosis (or both) in vitro and in vivo in breast, ovary, lung, colonic and gastric cell lines, with generally mild and reversible toxicity (Woodburn et al. 1998, Ciardiello et al. 2001).

\section{Growth factor receptor inhibitors decrease epithelial proliferation in ductal carcinoma in situ}

A recent study has investigated the effects of c-erbB-2 monoclonal antibody therapy and EGFR tyrosine kinase inhibition on epithelial proliferation and apoptosis in DCIS (Chan et al. 2001), using the DCIS xenograft model described previously (Holland et al. 1997, Gandhi et al. 2000).

The effects of 4D5 monoclonal antibody directed against an epitope on the extracellular domain of c-erbB-2 (trastuzumab) were investigated. Positive control experiments were conducted in which SKOV3 human ovarian carcinoma cells were implanted into athymic nude mice and allowed to form tumours for 14 days. Intraperitoneal injection of 4D5 monoclonal antibody resulted in significant tumour growth inhibition in SKOV3 cells after 21 days of treatment $(P<0.01)$. Of seven DCIS xenograft experiments in which 4D5 monoclonal antibody was used, five (71\%) were immunohistochemically c-erbB-2-positive, with all seven DCIS specimens being of the comedo type and ER-negative.

After 28 days of treatment with anti-c-erbB-2 monoclonal antibody, the median labelling index in c-erbB-2-positive DCIS was 24.5 (interquartile range 11.636.8), compared with 19.9 (interquartile range 15.0-35.2) in the control group $(P=0.88)$. The median apoptotic index was 0.72 (interquartile range $0.40-1.07$ ) in the 4D5-treated group, compared with 0.96 (interquartile range 0.83-1.77) in the control group $(P=0.14)$. Therefore, non-significant effects on epithelial proliferation and apoptosis were observed with 4D5 monoclonal antibody in ER-negative DCIS xenografts. Similar data were obtained with c-erbB-2-negative 4D5-treated xenografts compared with control DCIS xenografts. 
The lack of response may relate to the intact basement membrane of DCIS, which may present a physical barrier to the large molecule of 4D5 antibody, thus precluding its penetration into the DCIS basement membrane and its interaction with the c-erbB-2 receptor (Holland et al. 1997). Alternatively, c-erbB-2 oncoprotein may not be the main receptor driving epithelial proliferation in DCIS (Robertson et al. 1996).

In the same study, the effects of the novel EGFR tyrosine kinase inhibitor (EGFR-TKI) ZD1839 (Iressa; AstraZeneca) on epithelial proliferation and apoptosis were investigated. ZD1839 has a molecular weight of $446 \mathrm{kDa}$ and, therefore, has a greater likelihood of penetrating through the basement membrane of DCIS. It is an orally active and selective EGFR-TKI, with 100 times greater specificity for EGFR tyrosine kinase than c-erbB-2 tyrosine kinase, and 1000 times greater specificity for EGFR tyrosine kinase than c-flt-1 tyrosine kinase (Woodburn et al. 2000).

Positive control experiments with the human breast carcinoma cell line MDAMB231 demonstrated a significant inhibition of tumour volume growth after 7 days of treatment with ZD1839 $(P<0.01)$. The proliferation index (as judged by Ki67 staining) was significantly decreased by ZD1839 compared with that in control-treated tumours. Treatment with ZD1839 (but not vehicle control) decreased phosphorylated EGFR and MAP kinase activity in the tumours. Almost all $(10 / 11 ; 91 \%)$ of DCIS xenograft experiments in which ZD1839 was used were immunohistochemically positive for EGFR. Eight of ten EGFR-positive DCIS xenografts were ER-negative.

After 14 days of treatment (day 28) with ZD1839 (100$200 \mathrm{mg} / \mathrm{kg}$ ), a significant decrease in proliferation was detected compared with controls $(P<0.01)$ (Fig. 3). This decrease was maintained when treatment was extended to 28 days (day 42) at ZD1839 $75 \mathrm{mg} / \mathrm{kg}(P<0.05)$. The median apoptotic index increased after 7 days of treatment (day 21) in the ZD1839-treated group compared with controls. The labelling index and apoptotic index data were similar to those obtained with EGFR-negative DCIS xenografts and ER-positive DCIS treated with ZD1839.

These data clearly show that EGFR tyrosine kinase inhibition with ZD1839 decreases proliferation and activates apoptosis in DCIS in vivo. These findings suggest that ZD1839 is a potential agent for the treatment and chemoprevention of DCIS. In support of these observations are data from a recent in vitro study showing a significantly marked decrease in proliferation with ZD1839 in MCF7 breast cancer cells, thereby strongly suggesting that cell proliferation in breast cancer is driven via EGFR signalling pathways (Gee et al. 2001, McClelland et al. 2001).

It has previously been shown that the preferred heterodimerisation partner for all type I tyrosine kinase receptors, including EGFR, is c-erbB-2 (Graus-Porta et al. 1997). It is possible that ZD1839 may inhibit

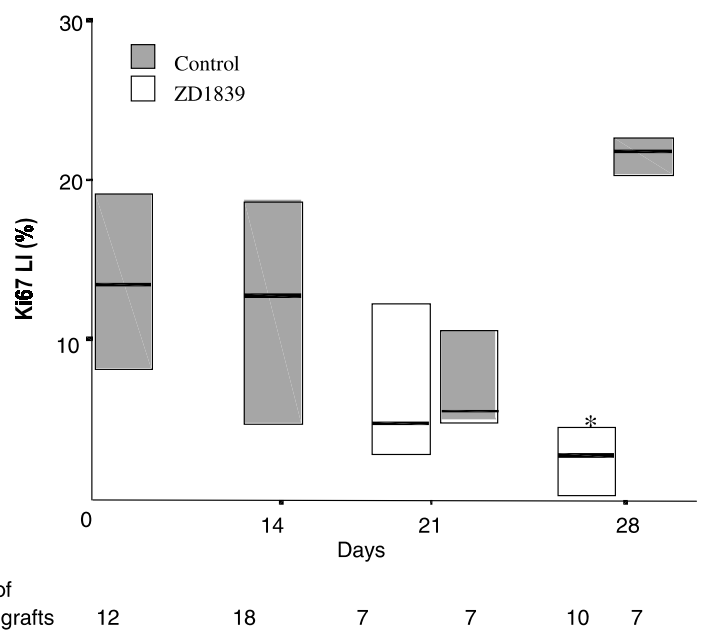

Figure 3 Effect of ZD1839 (200 mg/kg daily) on epithelial proliferation (Ki67 labelling index, LI) of DCIS retrieved xenografts. ZD1839 or vehicle was given from day 14 onwards. Horizontal lines represent median values and boxes denote the interquartile ranges. The number of xenografts used for each time point is presented beneath the chart. A significant decrease in proliferation was detected in the ZD1839 group after 14 days of treatment (day 28) compared with controls $\left({ }^{*} P<0.01\right.$, Mann-Whitney $U$ test).

EGFR-mediated phosphorylation and activation of c-erbB-2 within EGFR-c-erbB-2 heterodimers, resulting in decreased proliferation and increased apoptosis. In support of this we have found that ZD1839 inhibits the proliferation of breast cancer cell lines that over-express c-erb-B2 (Fig. 4 and Anderson et al. 2001).

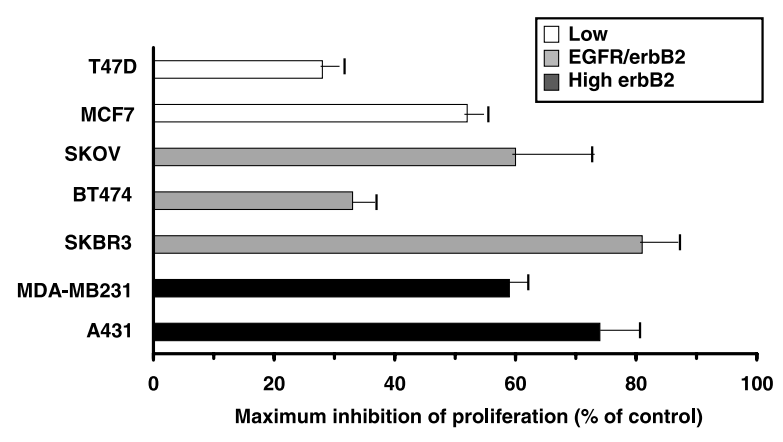

Figure 4 Anti-proliferative effects of ZD1839 in EGFR-positive cancer cells with varying levels of c-erbB-2 expression. Low-density cell cultures growing in medium containing $10 \%$ foetal calf serum were treated for $48 \mathrm{~h}$ with ZD1839 $(1 \mu \mathrm{mol} / \mathrm{l})$. Cell numbers were then counted and related to cultures treated with drug vehicle $(0.1 \% \mathrm{DMSO})$. All values are means \pm S.E.M. from at least three independent experiments. The relative levels of expression of EGFR and erbB-2 (+++, high; ++, medium; +, low) were determined by immunoblotting. 


\section{Bundred et al.: EGFR inhibition in ductal carcinoma in situ}

Importantly, despite the fact that EGFR is expressed in many tissues, no drug-related toxicity was detected in the mice treated with ZD1839 (Chan et al. 2001). Phase I clinical trials of ZD1839 have shown that its toxicity is manageable, with the most common side effects including acne-like rash, diarrhoea, nausea and vomiting (Baselga et al. 2000, Ferry et al. 2000, Goss et al. 2000; Negoro et al. 2001). Phase II and III clinical trials of this drug are currently in progress.

\section{Discussion}

Accumulating evidence on the expression and function of EGFR in normal breast and DCIS supports the concept that the major modulating growth factor receptor in murine and human breast is EGFR. It has been shown that, compared with the low expression of c-erbB-2, EGFR is widely expressed in normal breast tissue (Gompel et al. 1996). Moreover, a quantification analysis in the human breast cancer has indicated that, unlike c-erbB-2 expression, EGFR expression in tumours is correlated directly with bromodeoxyuridine labelling index, a surrogate measure of epithelial proliferation (Robertson et al. 1996). Both EGFR and c-erbB-2 are expressed in ER-negative, comedo-type DCIS (Bobrow \& Millis 1995). EGFR is also expressed in ER-positive DCIS (Chan et al. 2001). Receptor signalling is facilitated through the interaction of EGFR and c-erbB-2 in the formation of heterodimers (Graus-Porta et al. 1997). The presence of increased EGF, TGF- $\alpha$, and EGF-like ligands in DCIS, combined with the expression of EGFR and over-expression of c-erbB-2, may explain the markedly increased proliferation and apoptosis detected in ER-negative DCIS.

Pre-clinical studies performed on human DCIS xenografts in nude mice in vivo suggest a potential role for novel agents that inhibit intracellular signal transduction pathways. More specifically, the orally active and selective EGFR-TKI ZD1839 has been shown to exert dual action on proliferation and apoptosis in EGFR-positive DCIS (Chan et al. 2001). The anti-proliferative action of this drug against EGFR-positive cell lines that over-express c-erbB-2 suggests that co-expression of c-erbB2 in EGFR-positive DCIS may not diminish the effectiveness of ZD1839 against this category of cancer. Therefore, EGFR-TKIs may have the potential as adjuvant therapy for the treatment and chemoprevention of DCIS. These findings on the growth control of ER-negative DCIS support further pre-clinical and clinical investigation of these agents as a novel therapy in DCIS (George et al. 2000).

\section{Acknowledgements}

We are grateful to the Cancer Research Campaign and Professor Christopher Potten for allowing us to conduct research in the Patterson Institute for Cancer Research, Manchester.

\section{References}

Anderson NG, Ahmed T, Chan K, Dobson R \& Bundred NJ 2001 ZD1839 (Iressa) a novel epidermal growth factor receptor tyrosine kinase inhibitor potently inhibits the growth of EGFR positive tumours. International Journal of Cancer (In Press).

Baselga J \& Mendelsohn J 1997 Type I receptor tyrosine kinases as targets for therapy in breast cancer. Journal of Mammary Gland Biology and Neoplasia 2 165-174.

Baselga J, Herbst R, LoRusso P, Rischin D, Ranson M, Plummer R, Raymond E, Maddox A, Kaye SB, Kieback DG, Harris A \& Ochs J 2000 Continuous administration of ZD1839 (Iressa), a novel oral epidermal growth factor receptor tyrosine kinase inhibitor (EGFR-TKI), in patients with five selected tumour types: evidence of activity and good tolerability. Proceedings of the American Society of Clinical Oncology 19 177A (abstract 686).

Benz CC, Scott GK, Sarup JC, Johnson RM, Tripathy D, Coronado E, Shepard HM \& Osborne CK 1992 Estrogen-dependent, tamoxifen-resistant tumorigenic growth of MCF-7 cells transfected with HER2/neu. Breast Cancer Research and Treatment 24 85-95.

Bobrow LG \& Millis RR 1995 The pathology of ductal carcinoma in situ of the breast. Clinical Oncology 7 232-235.

Chan KC, Knox WF, Gandhi A, Slamon DJ, Potten CS \& Bundred NJ 2001 Blockade of growth factor receptors in ductal carcinoma in situ inhibits epithelial proliferation. British Journal of Surgery $88412-418$

Ciardiello F, Caputo R, Bianco R, Damiano V, Fontanini G, Cuccato S, De Placido S, Bianco AR \& Tortora G 2001 Inhibition of growth factor production and angiogenesis in human cancer cells by ZD1839 ('Iressa'), a selective epidermal growth factor receptor tyrosine kinase inhibitor. Clinical Cancer Research 7 149-165.

Clarke RB, Howell A, Potten CS \& Anderson E 1997 Dissociation between steroid receptor expression and cell proliferation in the human breast. Cancer Research 57 4987-4991.

Cobleigh MA, Vogel CL, Tripathy D, Robert NJ, Scholl S, Fehrenbacher L, Wolter JM, Paton V, Shak S, Lieberman G \& Slamon DJ 1999 Multinational study of the efficacy and safety of humanized anti-HER2 monoclonal antibody in women who have HER2-overexpressing metastatic breast cancer that has progressed after chemotherapy for metastatic disease. Journal of Clinical Oncology 17 2639-2648.

Dankort DL \& Muller WJ 2000 Signal transduction in mammary tumorigenesis: a transgenic perspective. Oncogene 19 1038-1044.

Dougall WC, Qian X \& Greene MI 1993 Interaction of the neu/p185 and EGF receptor tyrosine kinases: implications for cellular transformation and tumor therapy. Journal of Cellular Biochemistry 53 61-73.

Ernster VL, Barclay J, Kerlikowske K, Grady D \& Henderson C 1996 Incidence of and treatment for ductal carcinoma in situ of the breast. Journal of the American Medical Association 275 913-918. Ettinger B, Black DM, Mitlak BH, Knickerbocker RK, Nickelsen T, Genant HK, Christiansen C, Delmas PD, Zanchetta JR, Stakkestad J, Gluer CC, Krueger K, Cohen FJ, Eckert S, Ensrud KE, Avioli LV, Lips P \& Cummings SR 1999 Reduction of vertebral fracture risk in postmenopausal women with osteoporosis treated with raloxifene: results from a 3-year randomized clinical trial. Multiple Outcomes of Raloxifene Evaluation (MORE) Investigators. Journal of the American Medical Association 282 637-645.

Ferry D, Hammond L, Ranson M, Kris M, Miller V, Murray P, Tullo A, Feyereislova A, Averbuch S \& Rowinsky R 2000 Intermittent oral ZD1839 (Iressa), a novel oral epidermal growth factor receptor tyrosine kinase inhibitor (EGFR-TKI), shows evidence of 
Endocrine-Related Cancer (2001) 8 183-189

good tolerability and activity: final results from a Phase I study. Proceedings of the American Society of Clinical Oncology 19 3A (abstract 5e).

Fisher B, Costantino JP, Wickerham DL, Redmond CK, Kavanah M, Cronin WM, Vogel V, Robidoux A, Dimitrov N, Atkins J, Daly M, Wieand S, Tan-Chiu E, Ford L \& Wolmark N 1998 Tamoxifen for prevention of breast cancer: report of the National Surgical Adjuvant Breast and Bowel Project P-1 Study. Journal of the National Cancer Institute 90 1371-1388.

Fisher B, Dignam J, Wolmark N, Wickerham DL, Fisher ER, Mamounas E, Smith R, Begovic M, Dimitrov NV, Margolese RG, Kardinal CG, Kavanah MT, Fehrenbacher L \& Oishi RH 1999 Tamoxifen in treatment of intraductal breast cancer: National Surgical Adjuvant Breast and Bowel Project B-24 randomised controlled trial. Lancet 353 1993-2000.

Gandhi A, Holland PA, Knox WF, Potten CS \& Bundred NJ 2000 Effects of a pure antiestrogen on apoptosis and proliferation within human breast ductal carcinoma in situ. Cancer Research 604284 4288.

Gee JM, Hutcheson IR, Knowlden JM, Barrow D, Harper ME, Wakeling AE \& Nicholson RI 2001 The EGFR-selective tyrosine kinase inhibitor ZD1839 ('Iressa') is an effective inhibitor of tamoxifen-resistant breast cancer growth. Proceedings of the American Society of Clinical Oncology 20 71 A (abstract 282).

George WD, Houghton J, Cuzick J \& Forbes J 2000 Radiotherapy and tamoxifen following complete local excision (CLE) in the management of ductal carcinoma in situ (DCIS): preliminary results from the UK DCIS trial [abstract]. Proceedings of the American Society of Clinical Oncology 19 A270.

Gompel A, Martin A, Simon P, Schoevaert D, Plu-Bureau G, Hugol D, Audouin J, Leygue E, Truc JB \& Poitout P 1996 Epidermal growth factor receptor and c-erbB-2 expression in normal breast tissue during the menstrual cycle. Breast Cancer Research and Treatment 38 227-235.

Goss G, Lorimer I, Miller W, Hirte H, Stewart D, Batist G, Matthews S, Averbuch S \& Seymour L 2000 A phase I dose-escalation, pharmacokinetic (PK) and pharmacodynamic (PD) study of ZD1839 ('Iressa'): NCIC-CTG IND.122. Clinical Cancer Research 6 (abstract 382).

Graus-Porta D, Beerli RR, Daly JM \& Hynes NE 1997 ErbB-2, the preferred heterodimerization partner of all ErbB receptors, is a mediator of lateral signaling. European Molecular Biology Organization Journal 16 1647-1655.

Hanna W, Kahn HJ, Andrulis I \& Pawson T 1990 Distribution and patterns of staining of Neu oncogene product in benign and malignant breast diseases. Modern Pathology 3 455-461.

Holland PA, Knox WF, Potten CS, Howell A, Anderson E, Baildam AD \& Bundred NJ 1997 Assessment of hormone dependence of comedo ductal carcinoma in situ of the breast. Journal of the National Cancer Institute 89 1059-1065.

Laidlaw IJ, Clarke RB, Howell A, Owen AW, Potten CS \& Anderson E 1995 The proliferation of normal human breast tissue implanted into athymic nude mice is stimulated by estrogen but not progesterone. Endocrinology 136 164-171.

McClelland RA, Barrow D, Madden TA, Dutkowski CM, Pamment J, Knowlden JM, Gee JM \& Nicholson RI 2001 Enhanced epidermal growth factor receptor signaling in $\mathrm{mcf} 7$ breast cancer cells after long-term culture in the presence of the pure antiestrogen ICI 182,780 (Faslodex). Endocrinology 1422776 2788.

Muthuswamy SK, Siegel PM, Dankort DL, Webster MA \& Muller WJ 1994 Mammary tumors expressing the neu proto-oncogene possess elevated c-Src tyrosine kinase activity. Molecular Cell Biology 14 735-743.

Negoro S, Nakagawa K, Fukuoka M, Kudoh S, Tamura T, Yoshimua N, Takeda K, Tanigawara Y \& Swaisland H 2001 Final results of a Phase I intermittent dose-escalation trial of ZD1839 ('Iressa') in Japanese patients with various solid tumors. Proceedings of the American Society of Clinical Oncology 20 324A (abstract 1292).

Pavelic ZP, Pavelic L, Lower EE, Gapany M, Gapany S, Barker EA \& Preisler HD 1992 c-myc, c-erbB-2, and Ki-67 expression in normal breast tissue and in invasive and noninvasive breast carcinoma. Cancer Research 52 2597-2602.

Price P, Sinnett HD, Gusterson B, Walsh G, A'Hern RP \& McKinna JA 1990 Duct carcinoma in situ: predictors of local recurrence and progression in patients treated by surgery alone. British Journal of Cancer 61 869-872.

Robertson KW, Reeves JR, Smith G, Keith WN, Ozanne BW, Cooke TG \& Stanton PD 1996 Quantitative estimation of epidermal growth factor receptor and c-erbB-2 in human breast cancer. Cancer Research 56 3823-3830.

Roudabush FL, Pierce KL, Maudsley S, Khan KD \& Luttrell LM 2000 Transactivation of the EGF receptor mediates IGF-I-stimulated she phosphorylation and ERK1/2 activation in COS-7 cells. Journal of Biological Chemistry 275 22583-22589.

Siegel PM, Ryan ED, Cardiff RD \& Muller WJ 1999 Elevated expression of activated forms of Neu/ErbB-2 and ErbB-3 are involved in the induction of mammary tumors in transgenic mice: implications for human breast cancer. European Molecular Biology Organization Journal 18 2149-2164.

Silverstein MJ 1998 Ductal carcinoma in situ of the breast. British Medical Journal 317 734-739.

Ullrich A \& Schlessinger J 1990 Signal transduction by receptors with tyrosine kinase activity. Cell 61 203-212.

Wells A 1999 EGF receptor. International Journal of Biochemistry and Cell Biology 31 637-643.

Woodburn JR, Kendrew J, Fennel M, Kelly H \& Wakeling AE 2000 ZD1839 ('Iressa') a selective epidermal growth factor receptor tyrosine kinase inhibitor (EGFR-TKI): inhibition of c-fos mRNA, an intermediate marker of EGFR activation, correlates with tumor growth inhibition [abstract]. Proceedings of the American Association for Cancer Research 412557.

Woodburn JR, Morris CQ, Kelly H \& Laight A 1998 EGF receptor tyrosine kinase inhibitors as anti-cancer agents - preclinical and early clinical profile of ZD1839. Cellular and Molecular Biology Letter 3 348-349. 
